\title{
New therapeutic strategies to treat human cancers expressing mutant p53 proteins
}

\author{
Giovanni Blandino and Silvia Di Agostino ${ }^{*}$ (D)
}

\begin{abstract}
The tumor suppressor p53 plays a critical role to preserve DNA fidelity from diverse insults through the regulation of cell-cycle checkpoints, DNA repair, senescence and apoptosis. The TP53 is the most frequently inactivated gene in human cancers. This leads to the production of mutant p53 proteins that loose wild-type p53 tumor suppression functions and concomitantly acquire new oncogenic properties among which deregulated cell proliferation, increased chemoresistance, disruption of tissue architecture, promotion of migration, invasion and metastasis and several other pro-oncogenic activities. Mouse models show that the genetic reconstitution of the wild type p53 tumor suppression functions rescues tumor growth. This strongly supports the notion that either restoring wt-p53 activity or inhibiting mutant p53 oncogenic activity could provide an efficient strategy to treat human cancers. In this review we briefly summarize recent advances in the study of small molecules and compounds that subvert oncogenic activities of mutant p53 protein into wt-p53 tumor suppressor functions. We highlight inhibitors of signaling pathways aberrantly modulated by oncogenic mutant p53 proteins as promising therapeutic strategies. Finally, we consider the clinical applications of compounds targeting mutant p53 and the use of currently available drugs in the treatment of tumors expressing mutant p53 proteins.
\end{abstract}

\section{Background}

In the recent years, several consortia have led the sequencing of human cancer genomes identifying a myriad of genomic and chromosomal alterations in many human cancers [1-10]. Among them, the gene most commonly mutated is TP53: $96 \%$ in ovarian serous carcinoma [7], 85\% in small cell lung cancer [5], 75\% in pancreatic cancer [8], 60\% in head and neck squamous cell carcinoma [9], 54\% in invasive breast carcinoma [10], just to mention few tumor types. Approximately $70 \%$ of TP53 mutations are predominantly missense in one allele with loss of the second allele by loss of heterozygosity (LOH). Most of the missense mutations reside in the p53 DNA-binding region and can be classified as either contact (interfere directly with DNA binding) or conformational (induce local or global conformational distortions) mutations $[11,12]$. Several 'hotspot' mutations can be distinguished, such as R175, G245, R248, R249, R273 and R282, which represent about 30\% of all mutations in TP53 across all human cancer types [13].

\footnotetext{
* Correspondence: silvia.diagostino@ifo.gov.it

Oncogenomic and Epigenetic Unit, Department of Diagnostic Research and Technological Innovation, IRCCS Regina Elena National Cancer Institute, 00144 Rome, Italy
}

In several human tumours specific TP53 mutations have been associated to poor prognosis [14, 15]. In line with this, in patients affected by the Li-Fraumeni (LF) syndrome, germline missense p 53 mutations have been associated with earlier age of tumour onset when compared to germline TP53 loss [16]. The tumoral and metastatic phenotype of mutant TP53-bearing tumours can be also ascribed to specific mutant p53 proteinprotein interactions. Indeed, it has shown that mutp53 can drive the expression of key regulators of proliferation, invasion and metastasis through the binding to several transcription factors including NF-Y, E2Fs, NFkBp65, NfkBp50, SREBP, YAP, VDR or NRF2. This leads to increased proliferation, cholesterol synthesis, inhibition of autophagy and DNA repair machinery, accumulation of reactive oxygen species, and enhanced cell survival [17-26]. In this scenario mutant p53 functions as a co-factor able to sustain the expression of several pro-oncogenic genes that affect diverse signalling pathways whose aberrant activation contributes to increased proliferation, enhanced metastatic potential and acquisition of resistance to specific therapies.

Induction of cell migration by mutp53 is highly cell-context-dependent, and additional signals such as

\section{) Biomed Central}

(c) The Author(s). 2018 Open Access This article is distributed under the terms of the Creative Commons Attribution 4.0 International License (http://creativecommons.org/licenses/by/4.0/), which permits unrestricted use, distribution, and reproduction in any medium, provided you give appropriate credit to the original author(s) and the source, provide a link to the Creative Commons license, and indicate if changes were made. The Creative Commons Public Domain Dedication waiver (http://creativecommons.org/publicdomain/zero/1.0/) applies to the data made available in this article, unless otherwise stated. 
oncogenic Ras in combination with receptors including transforming growth factor $\beta$ (TGF $\beta$ ) receptor, epidermal growth factor receptor (EGFR), and MET might be required to support this activity [27-30]. Mechanistically, TGF $\beta$ acts in concert with oncogenic Ras and mutp53 to induce the assembly of a mutp53/p63 protein complex in which SMADS serve as platform to sequester and inhibit metastasis suppressor p63 target genes [27]. By inhibiting p63, mutp53 can regulate a proinvasive transcription program that includes regulation of the expression of Dicer, DEPDC1, Cyclin G2, and SHARP1 [27, 31]. The interaction of mutp53 with p63 also enhances the recycling and signalling of cell surface receptors, by engaging the RAB11 effector, RAB coupling protein (RCP). Indeed, expression of mutp53, or inhibition of p63, promotes RCP-mediated recycling of growth factor receptors such as the EGFR and MET [28-30]. Consistently, the binding of mutp53 to p73 inhibits the triggering of apoptosis p73-dependent in response to chemotherapeutic treatment [32, 33], an activity that requires TopBP1 to prevent binding of p73 to target gene promoters [34]. Although mutant p53 likely functions by modulating p63 and p73 activity, further studies are required to clarify effects on different isoforms and different outcomes.

Mutations of TP53 are typically seen in the later clinical stages of cancers and the genomic instability is one of the most important features of tumors expressing mutant p53 proteins [35]. According with the oncogeneinduced DNA damage model, activated oncogenes induce in both precancerous lesions and established cancers an aberrant DNA damage response (DDR), the failure of DNA replication forks regulation and the formation of DNA double strand breaks (DSBs) [6, 35-37]. This continuous accumulation of DNA alterations activates TP53, which exerts its safeguard mechanism by promoting apoptosis or senescence [6,35-37]. When this replicative stress contributes to increase the selective pressure to mutate TP53, the DDR is definitively compromised allowing cancers to develop and to spread [6,35-37]. The high prevalence and tumor specificity render mutant p53 proteins very attractive targets for cancer therapy. As mutant p53 is still rather difficult to tackle efficaciously, the identification of mutant p53 tumor dependencies might alternative targeting opportunities.

\section{Mutant p53 proteins in human cancers}

Among human cancers with TP53 missense mutations, about $60 \%$ show concomitant deletion of the other allele [38]. The remaining group (40\%) does not undergo LOH, retaining a wild-type TP53 allele. In cancer cells that do not undergo LOH of the wild-type TP53 allele, wild-type p53 expression and function may be inhibited through a dominant negative mechanism. Indeed, mutant p53 proteins are able to heterodimerize with wild-type p53 proteins, forming complexes that attenuate the function of wild-type p53 though conformational shifts or inhibiting the DNA-binding activity of wildtype p53 on target genes [39, 40].

Unlike wtp53 protein, mutant p53 is a rather stable protein. Efficient mutp53 GOF activity requires elevated levels of mutp53 protein in the cancer cell. Although transcriptional and translational mechanisms contribute to such increase, its main driving mechanism is believed to be the increased protein stability of mutp53. The majority of the regulatory pathways of p53 are shared between wt-and mutant p53 proteins. However, a number of key differences account for the chronic stabilization and activation of mutant p53, which drive its oncogenic GOF.

In primary cells derived from human Li-Fraumeni syndrome patients, who carry germline p53 mutations, the levels of mutp53 are rather low and comparable to those of wtp53 [41]. This and other works corroborate the hypothesis that mutp53 is not intrinsically stable, rather, alterations that occur within tumor cells lead to its stabilization. Accordingly, mutp53 protein levels are steady-state in mutp53 knockin mice, but significantly increase in tumors that arise in these mice $[36,42]$. Subsequent studies have shown that multiple oncogenic effects can stabilize mutant p53 in vivo and drive its oncogenic functions.

The degradation of wtp53 involves several E3 ubiquitin ligases that target p53 for polyubiquitylation and consequent proteasomal degradation, as well as ubiquitinindependent degradation in the proteasome. The most important driver of p53 degradation is the ubiquitin ligase mouse double-minute 2 (MDM2) that targets p53 to the proteasome for degradation [43-45]. MDM2 is itself a p53 target gene, its induction by p53 results in a negative feedback loop through which both proteins are kept to steady state levels [46]. However, mutp53 fails to transactivate the MDM2 gene. MDM2 protein levels are rather low in cells that express only mutp53. Indeed, ablation of endogenous ubiquitin ligases MDM2 and p16INK4a in mutp53 knockin mice leads to a substantial increase in endogenous mutp53 levels [36, 47]. The ubiquitination of mutp53 is also enhanced by the activity of other E3 ligases, CHIP and Cop1 although the overall efficiency of mutp53 ubiquitination is reduced compared with that of wt-p53 protein [45].

Mutation of p53 may affect its stability through a combination of mutant p53 inherent biochemical and biophysical properties as well as pathways aberrantly activated in genetically damaged cells. Hence, in primary cells derived from mutp53 knockin mice mutp53 can be stabilized by genotoxic stress better than wtp53 [42]. Furthermore p53 LOH seems to be a necessary 
prerequisite for mutant p53 stabilization and gain-offunction in vivo [48]. The heat shock protein HSP90 chaperone machinery is highly activated in cancer versus normal tissues, rendering them resistant to drugs by supporting proper folding of conformationally oncoproteins including mutp53 $[49,50]$. Both structural and DNA-contact classes of mutant p53 proteins require HSP90 to escape degradation by their E3 ubiquitin ligases [51]. Interestingly, the inhibition of HSP90 by 17AAG or siRNA against HSF1 (a major transcription factor for HSP) enhances the ubiquitination and degradation of mutp53 [52]. 17AAG and its hydrophilic derivative 17DMAG are ansamycin-derived highly specific first generation HSP90 inhibitors (Hsp90i) [53]. Likewise, histone deacetylase inhibitors (HDACi), including FDAapproved SAHA, are promising anti-cancer drugs whose actions involve hyperacetylation of histone and select non-histone targets including HDAC6 substrate HSP90, thus indirectly inhibiting HSP90 [54].

Further work will reveal additional mechanisms that lead to mutp53 stabilization in cancer cells, thereby sustaining its GOF activities.

\section{Downstream effector pathways related to mutant p53}

At a cellular level mutp53 GOF activity has been shown to abrogate all or most of the cellular responses mediated by wtp53 such as cell-cycle arrest, apoptosis, senescence, DNA repair, maintenance of centrosome number, restriction of phenotypic plasticity, and preservation of homeostatic balance $[14,55,56]$. In addition, the presence of mutant p53 compromises cellular responses to therapeutic agents [57-59], increases inflammation and angiogenesis $[19,59]$ and correlates with enhanced metastasis and aggressiveness [14, 60, 61].

Accumulating evidence has suggested the involvement of mevalonate pathway in cancer progression. Increased expression of mevalonate pathway-associated proteins is correlated with poor prognosis in breast cancer patients $[62,63]$. The mevalonate pathway is an essential lipogenic and uses acetyl-CoA to produce isoprenoids and cholesterol [62]. Isoprenoids are required for protein prenylation/lipidation (farnesylation and geranylgeranylation), which enables target proteins, including Ras and Rho small guanosine triphosphatases (GTPases), to anchor to the cell membrane. Cholesterol is used as an important hydrophobic precursor to bile acids, hormones, and lipoproteins [62].

Growing evidence reported the functional association between the mevalonate pathway and oncogenic proteins including mutp53, Ras, Rho, and YAP/TAZ [21, 64, 65]. Recently, through independent high-throughput screening of chemical compound libraries, statins have been identified as drugs that deplete mutp53 [66] and interfere with YAP/TAZ oncogenic activity in cancer cells $[22,23]$. Yes- associated protein (YAP) and its paralogue TAZ are transcriptional coactivators and downstream effectors of the Hippo signaling pathway which regulates organ growth, tissue regeneration, and stemness [67]. Also, the roles of YAP and TAZ in cancer progression are well defined [68]. In breast cancer cells, oncogenic mutant p53 acts as a positive transcriptional cofactor for SREBPs, leading to elevated expression of mevalonate enzymes [21] and SREBP-mevalonate axis is a relevant input for YAP/TAZ oncogenic activity [23]. Statins mainly deplete conformational or misfolded mutp53 with minimal impact on wtp53 and DNA-contact mutp53 that maintain native protein structure. Statin's effect is specific to the mevalonate pathway, because mutp53 depletion by statins is rescued by supplementation with MVA, a metabolite produced by HMGCoAR enzyme [66]. Although many clinical works support the positive roles of statins in human cancer suppression or patient's prognosis, the efficacy of statitin tretment might be different among type or dose of statins, cancer type, and type of genetic alterations in tumors $[66,69]$. Other inhibitors for the mevalonate pathway have been tested in clinical trials with promising results such as zoledronic acid, farnesyl transferase inhibitors (FTIs) and GGTI inhibitors. TP53 status, which is not considered in these clinical trials, might be an important variable to predict the response to mevalonate pathway inhibitors [70].

An increasing number of studies highlight the role of mutp53 proteins in the alteration of cancer cell secretome and in the modification of tumour microenvironment $[25,61]$. Solid tumours take advantage of a co-evolution of neoplastic and stromal cells. Extracellular matrix (ECM) also plays a dynamic role in cancer invasion [71]. Cancer cells secrete cytokines, chemokines, proteases, growth and angiogenic factors that are able to regulate the crosstalk between stroma/cancer cells and tumour microenvironment [72]. Recent evidence have demonstrated a key role of mutp53 in the aberrant modulation of the extracellular matrix (ECM) components $[60,73,74]$, in the secretion of pro-inflammatory, immunomodulatory interleukins and cytokines $[60,75,76]$ and in the regulation of the crosstalk between tumour and stromal cells [19, 60, 61, 77].

An additional pathway in which mutp53 plays a role is autophagy. Autophagy has been widely recognized as a main pathway involved in both the regulation of cancer cell proliferation and in the response to several anticancer drugs. It is an intracellular degradative process through which damaged macromolecules and organelles are targeted to lysosomes via autophagic vesicles.. Originally Kroemer and colleagues described the relationship between mutp53 proteins and autophagy. Indeed, they showed that the cytoplasmic localization of mutp53$\mathrm{R} 273 \mathrm{H}$ and mutp53-R273L inhibited the autophagy 
machinery [78]. On the contrary, the mutp53 proteins preferentially localized in the nucleus, such as mutp53P151H and mutp53-R282W, failed to counteract autophagy [78]. AMPK is a highly conserved serine/threonine protein kinase complex that, induced by metabolic stress, stimulates autophagy as tumor suppressor mechanism by phosphorylation of several downstream transcription factors, wtp53 among them, and metabolic enzymes [79]. Recently, It has been documented that both contact and conformational mutp53 proteins prevent autophagy in cancer cells through the constitutive inhibition of AMPK signaling [25]. Indeed, mutant p53 significantly counteracts the formation of autophagic vesicles and their fusion with lysosomes throughout the repression of some key autophagy-related proteins and enzymes such as BECN1 (and P-BECN1), DRAM1, ATG12, SESN1/2 and PAMPK. This also pairs with the stimulation of mTOR signalling pathway [25]. These finding are in agreement with a number of works indicating that mutp53 proteins exert their oncogenic functions also through the stimulation of $\mathrm{PI} 3 \mathrm{~K} / \mathrm{Akt} / \mathrm{mTOR}$ signaling in order to inhibit autophagy and promote cancer proliferation [59, 80]. Interestingly mutant p53-driven mTOR stimulation sensitizes cancer cells to the treatment with the mTOR inhibitor everolimus. This might suggest the use mTOR inhibitors for the treatment of patients carrying mutant p53 proteins [25]. Functionally, Choudhury and collegues showed that mutp53 stability increased in cells treated with the autophagic inhibitor chloroquine, while overexpression of key autophagic genes led to mutp53 protein degradation [81]. Moreover they found that glucose restriction leads to proteasome-independent but autophagy-dependent degradation of mutp53 proteins [82]. They reported that mutp53 binds proteins belonging to the autophagic apparatus in lysosomes [82]. These metabolic changes mutp53induced as a novel GOF to promote tumor development are a strong rationale to study glycolytic and mitochondrial oxidative phosphorylation pathways. The enhanced glucose metabolism under aerobic conditions (Warburg effect) is a common feature of many tumors to meet the high biosynthetic demand of rapidly dividing cells [83]. However increased glycolysis is observed in many types of cancer cells, but this metabolic shift can also cause increased oxidative stress and DNA damage [84]. A recent study reported that mutp53 promotes glycolysis and the Warburg effect in both cultured cells and mutant p53 R172H knock-in mice as an additional novel GOF of mutp53 [84]. Furthermore mutp53 induces the expression of glycolytic enzyme hexokinase II, which could increase glycolysis [85].

Collectively, these findings mirror a pivotal role of mutp53 in mediating cancer metabolic alteration, thereby depicting a novel mechanism underlying mutant p53 gain-of-function in human cancers (Fig. 1).

\section{Therapies to restore wild-type $p 53$ functions}

In preclinical studies reactivation of wild-type p53 in p53-null or p53 mutant tumors is sufficient to slow down or regress the tumor progression [86-90]. This finding has stimulated the research of multiple approaches to reactivate wild-type p53 functions in tumor cells carrying mutant $\mathrm{p} 53$ proteins.

Small molecules have been developed that specifically target mutant forms of p53 restoring p53 transcriptional activity, thereby leading to cell cycle arrest or apoptosis of tumor cells (Fig. 2).

The small molecules PRIMA- 1 and MIRA-1 have been identified in a cell-based screen of two thousands compounds from the National Cancer Institute (NCI) library $[91,92]$. Unfortunately MIRA-1 was not further followed up due to high toxicity $[92,93]$.

PRIMA-1 and its analogous PRIMA-1MET (APR-246), can restore mutant $\mathrm{p} 53$ proteins to a wild type conformation re-establishing a wt-p53 transcriptional activity. This leads to enhanced expression of Puma, Noxa and Bax in p53 mutant cells [93, 94]. Chemically PRIMA-1 is converted intracellular to Michael acceptor methylene quinu- clidinone (MQ) that binds covalently to cysteine residues of mutant p53 protein [95]. Using computational prediction of p53 structural models, a transiently open pocket close to Cys124, Cys135 and Cys141 was identified as a potential binding site for MQ [96]. Binding of MQ leads to refolding of the mutant proteins. This refolding is highlighted by a differential interaction between APR-246 pre-treated and post-treated p53 with conformation-specific antip53 antibodies and by mass spectrometry analysis [97].

In vivo, APR-246 has shown impressive cytotoxic and apoptotic effects in murine cancer models of such as mutant p53 small cell lung carcinoma [97], multiple myeloma [98] and breast cancer [99]. APR-246 was tested in 2012 in a phase I/Ila clinical trial of 22 patients with hematologic malignancies and prostate cancer (TP53 mutation status was not a pre-selection criterion). The drug was generally well tolerated with only transient side effects such as fatigue, dizziness, headache, and confusion. Two minor responses were observed in these late stage patients, one in an acute myeloid leukemia (AML) patient carrying V173 M mutant p53 and the other one in a non-Hodgkin lymphoma patient with a TP53 splice site mutation [100]. Currently patients are enrolled in diverse clinical studies:

1. Phase Ib/II study for the treatment of either platinum resistant advanced and metastatic oesophageal or gastro-oesophageal junction cancers bearing mutant p53 proteins (NCT02999893).

2. Phase Ib/II study for the treatment of platinum sensitive recurrent high-grade serous ovarian cancers 


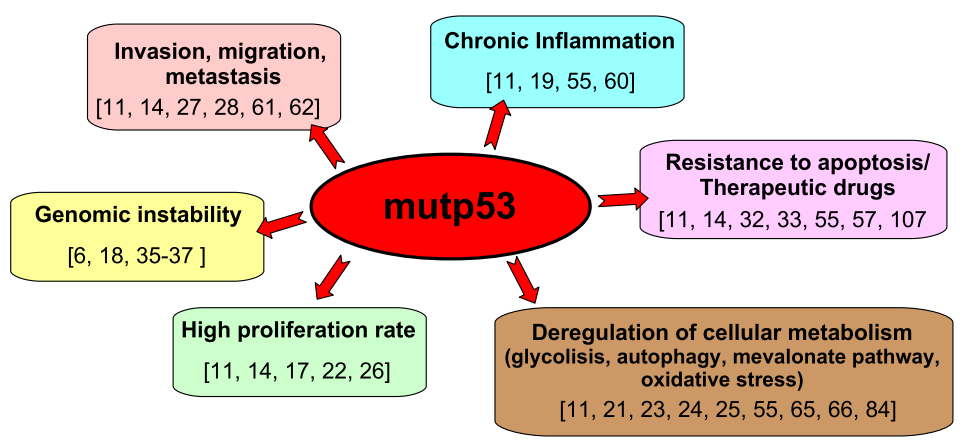

Fig. 1 Mutant p53 involvement in pathways associated with cancer development. Mutant p53 regulates many cellular processes, such as proliferation, migration, invasion, survival, metabolism, chemoresistance, and tissue architecture, to promote tumor progression

with mutated p53 with APR-246 in combination with carboplatin and pegylated liposomal Doxorubicin Hydrochloride (PLD) (NCT02098343).

3. Phase $1 \mathrm{~b} / \mathrm{II}$ study for the safety and efficacy of APR-246 w/azacitidine in mutant p53 myeloid neoplasms (NCT03072043).

4. Phase II study in platinum-resistant high-grade serous ovarian cancers with APR-246 in combination with PLD (NCT03268382).

These clinical trials are still enrolling patients and no data have been released yet.

Recently, by multi-omics approaches, the proteasome machinery has been identified as a common target of diverse mutant p53 missense proteins in triple-negative breast cancers (TNBC) [24]. Proteasome inhibitors such as bortezomib and carfilzomib are FDA- clinically approved drugs for the treatment of multiple myeloma [101]. Although several studies support a therapeutic potential of the proteasome inhibitors in solid tumours the described resistance mechanisms have not allowed these therapies to progress beyond clinical trials [101]. Walerych and colleagues reported that the cooperation of mutp53 with Nrf2 (NFE2L2) activates proteasome gene transcription, resulting in resistance to the proteasome inhibitor carfilzomibin in TNBC [24]. On the basis of these findings, the authors simultaneously targeted mutp53 proteins and their downstream pathway-the proteasome-in TNBC cells with APR-246, thereby overcoming resistance to pharmacological inhibition of the proteasome [24]. This treatment strategy may also overcome the limitations of therapies that target only mutp53 in solid tumours [102].

\section{Peptides and molecules to "correct" mutant p53 activities} Most of the gain-of-function mutant p53 proteins derive from missense mutations residing in the core domain [14]. These point mutations found in the core domain thermally destabilize p53. The core domain of wild-type p53 has a melting temperature of $44{ }^{\circ} \mathrm{C}$ and a short halflife of 9 min at $37{ }^{\circ} \mathrm{C} \mathrm{[102]} \mathrm{while} \mathrm{mutant} \mathrm{p53} \mathrm{has} \mathrm{an} \mathrm{in-}$ creased half-life which strongly contributes to the emergence of gain-of-function phenotypes [103, 104].

This might be one of the main interest to discover peptides and small molecules that can stabilize mutant p53 in its active biological conformation, thus restoring its DNA-binding ability and potentially rescuing wild type p53 activity (Fig. 2).

p73 and p63 proteins show a high degree of structural and functional homology to p53, in particular within the

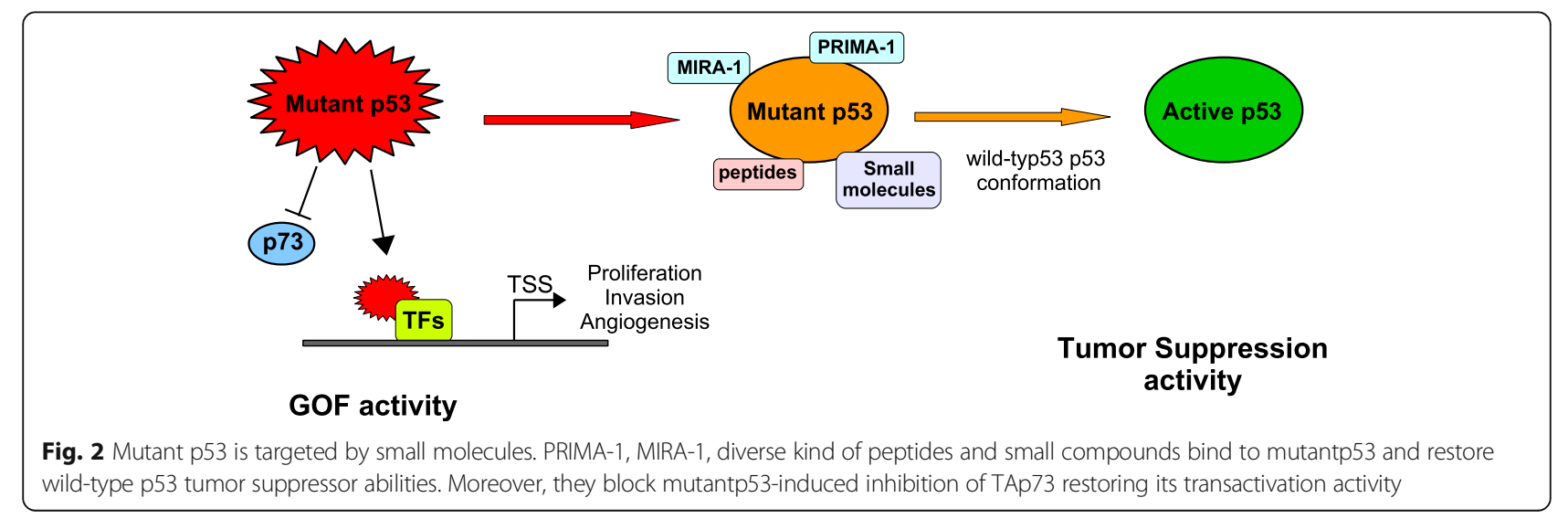


DBD (around 65\%) [105]. p63 and p73 can form homoand heterotetramers only with each other, but mutp53 can interact with both p63 and p73 different isoforms sequestering them and inhibiting their transcriptional activity $[12,105,106]$. This broad inhibition of p53 family proteins results in enhanced proliferation and resistance to chemotherapy [12, 107]. Thus, inhibition of the mutp53/p73 and of mutp53/p63 protein complexes might be a promising alternative to the mutp53 refolding approach [108].

We have engineered short synthetic peptides (10-15 residues) capable to physically disassemble the protein complex mutp53/p73 [109]. The sequence of the short peptides recapitulates that of the specific DNA binding domain of p73 that is directly involved with the interaction with mutant p53 protein. Transduction of the short interfering peptides (SIMPs-Short Interfering Mutantp53 Peptides) in tumor cells bearing mutant p53 proteins enhanced cisplatin and adriamycin-induced apoptotic response. This occurred through the specific disassembling of the protein complex mutp53R175H/ p73 by SIMP5 and of the protein complex mutp53R $273 \mathrm{H} / \mathrm{p} 73$ by SIMP1 that provoked the restoration of p73-mediated transcription and apoptosis [110]. SIMPs did not have any effects on both p53 null and wtp53 expressing cells, thereby indicating that SIMPs activity is strictly connected to the presence of mutant p53 protein.

With a different approach, Del Sal's group reported that short peptide aptamers (PA) able to bind to different p53 mutants, whereas not to wt p53, were identified and characterized [110]. PAs consist of a short variable peptide domain usually expressed in the context of a protein scaffold and they are selected from highcomplexity libraries to specifically target proteins and modulate their activity [111]. The identified PAs specifically interfere with mutant p53 transcriptional functions and they have a specific ability to induce cell death in different cell lines expressing mutant p53, whereas the same PAs failed to produce any effect in cells bearing wt p53 or in p53-null cells.

Recently, Tal and coworkers approached a phage display screening to select mutp53-reactivating peptides [112]. They found that the analyzed common p53 mutants were bound and reactivated by these peptides. Moreover, they promoted selective apoptotic death of cancer cells carrying mutant p53, and decreased the growth of human cell line-derived mouse xenograft tumors representing several types of highly aggressive cancer types. Remarkably, some peptides bear similarity to the sequences of human proteins known to interact with p53 suggesting that the peptides selected can indeed interact with p53 in a functionally relevant manner [112].
The hypothetical mechanism underlying the activity of all these peptides might be accounted for the fact that proteins of a typical population of mutant p53 in the cell are in a constant dynamic equilibrium between the misfolded and properly folded conformations. The peptides by binding preferentially to mutant p53 when it transiently exhibits a wild type conformation might stabilize it and gradually shifts the population equilibrium towards the wild-type conformation.

It is estimated that 75,000 new cancer cases per year bear Y220C p53 mutation. This mutation, in the core domain of p53 is not involved in DNA binding, but it creates a cavity that destabilizes p53 protein. The small molecules PhiKan083 and PhiKan7088 bind to this cavity and therefore interact with Y220C p53. In vitro, PhiKan7088 corrected the folding of Y220C p53 restoring transactivation potential inducing p21 and Noxa expression with the consequent cell cycle arrest and apoptosis [113].

Recently, El-Deiry group has described two additional mutant p53-targeting small molecules: (a) prodigiosin that disrupts the interaction of mutant p53 with the p53 family member $\mathrm{p} 73$, and thereby unleashes the cytotoxic and cytostatic activities of p73 [114]; (b) NSC59984 that augments mutant p53 degradation and also unleashes p73 activity [115].

Garufi et al., found that capsaicin, the major constituent of peppers, induced mutant p53 degradation and restored wild type p53 functions such as DNA binding and transactivation of target genes [11]. Furthermore, in combination with chemotherapeutic agents, capsaicin induced cell death suggesting that capsaicin-induced p53 reactivation may improve mutp53-carrying cancer cell response to chemotherapy [116].

The role of mutant p53 protein as a target for dietaryrelated cancer chemopreventive compounds is a new field of research. Aggarwal and collegues have recently showed that cruciferous-vegetable-derived phenethyl isothiocyanate (PEITC) can reactivate p53 mutant under in vitro and in vivo conditions, revealing a new mechanism of action for a dietary-related compound [117]. PEITC exhibited growth-inhibitory activity in cells expressing p53 mutants with preferential activity toward mutant p53R175H. Mechanistic studies revealed that PEITC induced apoptosis in a p53R175H mutant-dependent manner by restoring wtp53 conformation and transactivation functions. Interestingly, the growth inhibitory effects of PEITC depended on the redox state of the cell. PEITC treatments render the mutant $\mathrm{p} 53 \mathrm{R} 175 \mathrm{H}$ sensitive to degradation by the proteasome in a concentrationdependent manner. Furthermore, the dietary supplementation of PEITC was able to reactivate WT p53 activity in vivo as well, inhibiting tumor growth in xenograft mouse model [117]. These findings provide the first 
example of mutant p53 reactivation by a dietary compound and have important implications for cancer prevention and therapy.

Bringing small peptides and molecules into the clinic remains challenging, mainly owing to the need to deliver the peptides efficiently into the tumor cells. However, their greater specificity bears the hope for minimal nonspecific toxicity, rendering such approach highly promising in the long run.

\section{Genomic instability to target mutant p53 in human cancers}

Genomic instability may arise from different pathways as centrosome amplification, epigenetic modifications, telomere dysfunction and DNA damage from endogenous and exogenous sources. In the presence of genomic instability there is an increase in the rate of DNA alterations compared to normal cells [118]. Oncogenic mutantp53 proteins promote both chromosomal (CIN) and amplification (AIN) instabilities [35-37]. Notably, expression of mutp53R172H (corresponding to human $\mathrm{R} 175 \mathrm{H}$ ) in p53-null primary mouse mammary epithelial cells and developing mouse mammary tumours resulted in aberrant centrosome amplification, multipolar mitoses and increased numbers of chromosomes [38, 39].

In vitro data also suggest that mutp53 can facilitate structural chromosomal abnormalities by interacting with and inhibiting the genome caretaker proteins of DNA repair. The fidelity of DNA double strand break (DSB) repair plays a central role in preventing translocations. In response to DNA double strand break signals, cells have at their disposal two distinct repair mechanisms: homologous recombination (HR) and nonhomologous end joining (NHEJ) [119]. MRE11 is a DNA binding protein involved in both HR and NHEJ [120]. Some mutant p53 proteins have been shown to bind MRE11 sequestering it from the DNA site of double strand breaks, thus increasing the amount of spontaneous chromosome, chromatid breaks and translocations, which happens in MRE11 null cells [121]. By this way mutant p53 abolishes the phosphorylation signaling which culminates with activation of ATM, the principal double strand break sensor in cells to activate HR, resulting in bypassing of the G2/M DNA damage checkpoint and a decrease of genomic stability [122].

Recently, we have documented that transcriptional activity of GOF mutant p53 proteins plays a role in the inefficient activation of DNA repair mechanism and consequent DNA damage accumulation in proliferating tumour cells [18]. In search for co-factors sharing mutant p53-induced transcriptomic alterations in cancer cells, we identified the transcriptional inhibitor E2F4 as a new partner of mutant p53 proteins in diverse types of tumor cells. E2F4 plays an important role in the suppression of proliferation-associated genes and recent evidences report that E2F4 may play an oncogenic rather than a tumor suppressor role in cancer cells [123]. Mutant p53/E2F4 oncogenic complex is able to bind rad17 and brcal gene promoters inhibiting their expression. Both BRCA1 and RAD17 proteins are key signal transducers during checkpoint activation in the response to DNA DSBs [124]. Furthermore the concomitant recruitment of mutant p53 and E2F4 proteins onto rad17 and brca1 gene promoters provided a global increase of histone $\mathrm{H} 3$ methylation and a decrease of histone $\mathrm{H} 4$ acetylation [18]. This might contribute to chromatin transcriptional inactive status of $\mathrm{rad} 17$ and $b r c a 1$ promoter regions.

From a clinical point of view, it was considered a cohort of tumors from head and neck squamous cell carcinoma (HNSCC) patients where TP53 status was assessed by direct sequencing of exons 2 through 11 [125]. HNSCC is characterized by a high grade of genomic instability and a TP53 mutation incidence of nearly $62 \%$ [126]. In these patients rad17 and brcal were expressed at lower level in tumors when compared to non-tumoral matched samples. This was significantly striking in the group of patients carrying mutant p53 proteins independently from other clinic-pathological parameters. Unlike those with mutant p53, wild type p53 tumors did not show any significant difference for rad17 expression between tumor and normal groups. Interestingly, brca1 transcript was upregulated in wild type p53 tumors [18]. Collectively, these findings strongly support the hypothesis of an active repression of rad17 and brcal gene expression by mutant p53 proteins, leading to a continuous DNA DSBs accumulation with a permanent increase in genomic instability.

Poly (ADP-ribose) polymerase 1 and 2 (PARP) are nuclear proteins that are activated by DSBs [127]. PARP1 has the function to protect DNA breaks and chromatin structure and to recruit DNA repair and checkpoint proteins to the sites of damage [128]. Interestingly, inhibition of PARP1 was found to be synthetically lethal for cells with defects in homologous recombination HR [129], a DSBs repair mechanism, and was particularly effective in tumor cells that lack functional BRCA1 or BRCA2 [129, 130]. DSBs repair depends on HR and NHEJ. To explain the synthetic lethality effect of PARPinhibitors it has to say that PARP1 is involved in NHEJ [131], cancer cells with deficiency in BRCA or HR will thus require PARP1-dependent NHEJ for DSBs repair, and become more vulnerable to apoptosis when PARP1 is inhibited [129] (Fig. 3A). If the DNA repair function of HR is intact, the inhibition of PARP1 alone may not necessarily induce cell death. PARP1 inhibitors such as olaparib and niraparib have been tested in clinical trials in breast and ovarian cancers [132, 133] (Fig. 3A). 



Fig. 3 Selective killing of mutant p53 tumor cells through cell-cycle checkpoint abrogation. (a) Endogenous single strand breaks (SSBs) are repaired by SSB repair pathways that involve PARP1. If base excision repair (BER) is impaired, through the inhibition of PARP (for example by olaparib), single strand breaks become double strand breaks. In patients with HR defects, such as a BRCA mutation carrier, this damage causes the cancer cell death since PARP inhibitors induce aberrant activation of NHEJ. (b) Compared to wtp53 cells with an intact G1 checkpoint, mutp53 cancer cells lacking the p53-dependent G1 checkpoint may depend more on the G2 checkpoint to survive after DNA damage. The inhibition of Wee1 activity could lead to mitotic catastrophe and cell death

Recently, olaparib was approved by the FDA as a monotherapy for the treatment of patients with deleterious or suspected deleterious germline BRCA mutation in advanced ovarian cancer who have been treated diverse prior lines of chemotherapy [134]. PARP inhibition is also promising for triple negative breast cancer (TNBC), which is an aggressive breast cancer characterized by high levels of replicative stress due to c-MYC amplification, EGFR activation and TP53 mutations (p53 gene was found to be mutated in approximately $80 \%$ of basal/ TNBC) $[135,136]$. Importantly, up to $20 \%$ of TNBC patients harbour germline BRCA mutations. Additionally, patients with sporadic TNBC without BRCA mutation show BRCA1 mutation-like tumor conditions ("BRCAness") in which BRCA is inactivated by other mechanisms such as promoter methylation or gene expression inhibition [18, 137, 138]. All these evidences strongly suggest that impaired HR from either BRCA mutation or BRCAness, PARP inhibition is believed to be a rational approach for this subtype of breast cancer. To confirm this, olaparib in phase II studies did not result in significant positive responses in non-BRCA-associated TNBC [139]. Combination strategies with olaparib and chemotherapeutic agents have shown to be effective in ERCC1 or PTEN-deficient lung cancer cells, showing that other deficiencies in DNA-repair pathways frequently occurring in NSCLC might have an impact on the response to olaparib treatment, and consequently also on this combination strategy [140, 141]. Therefore, further studies on the genetic profile of patient tumors might lead to the identification of other predictive markers besides the TP53 status.

The disruption of the nuclear architecture of telomeres might be another novel pathway through which TP53 mutants induce genomic instability in cancer cells. A pancreatic cancer model expressing endogenous expression of $\operatorname{Trp} 53(\mathrm{R} 172 \mathrm{H})$ and $\operatorname{Kras}(\mathrm{G} 12 \mathrm{D})$ demonstrated a high degree of genomic instability manifested by nonreciprocal translocations [142]. Furthermore, the authors showed that significant portions of telomeric sequences at the fusion points of translocations while the telomere sequences at the ends of chromatids were conserved, a phenotype observed in cells which lost the function of telomere capping proteins [143]. Previous reports showed the efficacy of the telomerase template antagonist, GRN163L, as a potential anticancer agent in metastatic breast cancer MDA-MB-231 cells expressing mutp53R280K [144, 145]. It was observed that GRN163L induced a rapid change in cellular architecture, leading to the hypothesis that GRN163L can augment the effects of the microtubule stabilizer paclitaxel in reducing the cell growth of breast cancer cells [144]. The combined treatment of GRN163L and paclitaxel resulted in a significant synergistic combination index (CI), in reducing the cellular proliferation and invasive potential of MDA-MB-231 breast cancer cells. Interestingly, a randomized Phase II study of imetelstat (grn163l) in combination with paclitaxel (with or without bevacizumab) in patients with locally recurrent or metastatic breast cancer has been completed and the results are expected (NCT01256762).

\section{Targeting WEE1 protein kinase to disarm mutant p53}

WEE1 is a tyrosine kinase with a pivotal role at the G2$M$ cell cycle checkpoint that prevents entry into mitosis in response to cellular DNA damage [124]. The progression from $G 2$ into $M$ phase is controlled by the Cdk1/ Cyclin B complex that is activated by dephosphorylation of tyrosine 15 (Tyr15) on Cdk1 by the Cdc25c phosphatase [124]. Before mitosis Cdk1 is maintained in an 
inactive state by WEE1 through phosphorylation of CDK1 at tyrosine 15 [124, 146]. WEE1 is highly expressed in several cancer types, including hepatocellular carcinoma [147], cervical cancers [148], lung cancers [149], squamous cell carcinoma [148, 150], colorectal cancers [151], gastric cancers [152], leukemia [153, 154], melanoma [155], and ovarian cancers [156]. High expression of WEE1 has been reported in some cancers in response to elevated replication stress, and has been associated with tumor progression and poor outcome [148, 155, 156] (Fig. 2B). Loss of WEE1 activity sensitizes p53 inactive cells to DNA damaging agents and radiosensitization [157-160]. Recently Moser and colleagues performed RNAi kinome viability screens in HNSCC to identify novel therapeutic drug targeting mutant p53 protein [150]. Kinase targets were selected on the basis of impaired viability and increased apoptosis following kinase knocking-down. Putative survival kinases included signaling proteins within the focal adhesion and integrin (CAMK2B, FYN, ILK, EPHA3, EIF2AK4, TRIB2), PI3K signaling (PIK4CB, PIK3CB, PIP5K1B, TRIB2, FGFR3, ALK), SRC signaling (FYN, TXK, CAM2KB), and G2/M cell cycle regulation (WEE1, NEK4, TTK, AURKA, CHK1). WEE1 was implicated as a critical survival kinase for TP53 mutant HNSCC cells. Treatment with WEE1 inhibitor MK-1775 caused unscheduled mitotic entry and apoptotic death selectively in mutp53 versus wild-type p53 cell lines. It also increased cisplatin-induced killing in a mutp53 orthotopic xenograft model [150]. In patients with HNSCC undergoing curative-intent surgery and heterogeneous adjuvant therapy, TP53 mutations were associated with reduced survival, independent of pathologic nodal stage or primary tumor site [161]. TP53 mutations were validated as a prognostic biomarker in a cohort of patients treated homogeneously with primary surgery and postoperative radiotherapy [162]. Further our group analyzed TP53 status by direct sequencing of exons 2 through 11 of a prospective series of 121 HNSCC samples and assessed its association with outcome in 109 followed-up patients [125]. A TP53 mutation was present in $58 \%$ of the tumors and TP53 mutations were significantly associated with a shorter recurrence-free survival [125]. In an orthotopic murine model evaluating 48 validated HNSCC cell lines, TP53 mutations correlated with higher growth rate, cervical nodal metastases, and decreased survival, suggesting a biologic basis for inferior prognosis [163]. Cells carrying wtp53 protein arrest at the G1 checkpoint of the cell cycle to repair damaged DNA, before DNA replication (Fig. 3B). Cells with defective p53 pathway as for those carrying mutant p53 proteins rely mainly on DNA repair at the G2 checkpoint [164]. Indeed several inhibitors of the G2 checkpoint sensitize mostly mutp53 tumor cells to DNA-damaging agents [165].

These evidences support the mitotic lethality rationale that cancers deficient in functional p53, a key component of the G1-S checkpoint, are more reliant on the G2-M checkpoint to repair DNA damage, and that abrogation of the G2-M checkpoint by WEE1 inhibition sensitizes p53-deficient cells to DNA-damaging agents [166] (Fig. 3B). In support of this, it has been previously documented that Cdk1/Cyclin B protein complex activity is higher in mutant p53 cells and is reduced by mutant p53 depletion [17, 22]. This suggests that abrogation of the G2-M checkpoint will selectively impact on tumor cells, with only limited effect on normal cells that have functional G1 and G2-M checkpoints. Therefore, inhibition of WEE1 kinase activity and removal of the G2-M checkpoint is an attractive strategy to drive cancer cells to enter into unscheduled mitosis and ultimately undergo cell death via mitotic catastrophe [167] (Fig. 3B). This principle was first demonstrated in mutp53 colorectal carcinoma, in which the preclinical WEE1 kinase inhibitor, PD0166285, potentiated radiation-induced killing by abrogating G2-M arrest and forcing premature mitotic entry [168].

A screening program that focused on the identification of WEE1 inhibitors from a small chemical compound library led to the discovery of the potent WEE1 inhibitor AZD1775 (also known as MK1775) [169]. There are currently 43 clinical studies listed in ClinicalTrials.gov for AZD1775 (MK1775), covering a wide range of cancer types including solid tumors, leukemia, childhood and adult brain tumors. In most of these studies AZD1775 is used in combination with carboplatin, cisplatin, docetaxel, 5-fluorouracil, gemcitabine, irinotecan, paclitaxel, pemetrexed, temozolomide, topotecan, or irradiation (clinicaltrials.gov). Of great interest those studies enrolling patients with TP53 mutations including: (a) the Phase II pharmacological study with MK-1775 combined with carboplatin in patients with p53 mutated epithelial ovarian cancer (NCT01164995); (b) the phase II study evaluating MK-1775 in combination with paclitaxel and carboplatin versus paclitaxel and carboplatin alone in adult patients with platinum sensitive p53 mutant ovarian cancer (NCT01357161); (c) the phase II single-arm study of AZD1775 monotherapy in relapsed small cell lung cancer patients with myc family amplification or CDKN2A mutation combined with TP53 mutation (NCT02688907); (d) the randomized phase II trial of cisplatin with or without WEE1 kinase inhibitor AZD1775 (MK-1775) for firstline treatment of recurrent or metastatic squamous cell cancer of the head and neck (NCT02196168). All these studies are actively enrolling patients and the related data will be expected. 


\section{Conclusions}

Because of its high mutation rate and its critical role in driving cancer formation/progression, the therapeutic targeting of mutant p53 is of absolute priority. Compounds reactivating mutant p53 to wild-type p53 tumor suppressor activities are actually available. Size, polarity, solubility, pharmacokinetic and pharmacodynamic properties of these compounds can be improved through medical chemistry approaches and drug-protein interaction studies. There are still many unresolved questions surrounding the role of mutant p53 in cancer. As the knowledge on the molecular mechanisms underlying gain of function mutant p53 protein progresses its therapeutic targeting will be much more precise and hopefully much more successful.

\section{Acknowledgements}

This work was supported by Italian Association for Cancer Research (AIRC) (Grant n. 16984) and Italian Ministry of Health (Grant n.GR-2011-02348813) to SDiA. This work was also supported by the Italian Association for Cancer Research (AIRC) (Grant n.20613) to GB, from Epigen Flagship Project (EPIGEN; sub-project 7.6) to GB, from MD Anderson SINF grant to GB and from $5 \times$ 1000 from Italian Ministry of Health.

\section{Authors' contributions}

Both SDiA and GB conceived, wrote and reviewed the manuscript. Both authors read and approved the final manuscript.

\section{Competing interests}

The authors declare that they have no competing interests.

\section{Publisher's Note}

Springer Nature remains neutral with regard to jurisdictional claims in published maps and institutional affiliations.

Received: 20 December 2017 Accepted: 12 February 2018

Published online: 15 February 2018

\section{References}

1. Wood LD, Parsons DW, Jones S, Lin J, Sjöblom T, et al. The genomic landscapes of human breast and colorectal cancers. Science. 2007;318: 1108-13.

2. Jones S, Zhang X, Parsons DW, Lin JC, Leary RJ, et al. Core signaling pathways in humanpancreatic cancers revealed by global genomic analyses. Science. 2008;321:1801-6.

3. Kandoth C, mclellan MD, Vandin F, Ye K, Niu B, et al. Mutational landscape and significance across 12 major cancer types. Nature. 2013;502:333-9.

4. Cancer Genome Atlas Research Network. Comprehensive genomic characterization defines human glioblastoma genes and core pathways. Nature 2013; 455:1061-1068.

5. Ding L, Getz G, Wheeler DA, Mardis ER, Mclellan MD, et al. Somatic mutations affect key pathways in lung adenocarcinoma. Nature. 2008;455: 1069-75.

6. NEgrini S, Gorgoulis VG, Halazonetis TD. Genomic instability: an evolving hallmark of cancer. Nat Rev Mol Cell Biol. 2010;11:220-8.

7. THe Cancer Genome Atlas Research Network. Integrated genomic analyses of ovarian carcinoma. Nature 2011; 474:609-615.

8. YAchida S, White CM, Naito Y, Zhong Y, Brosnan JA, et al. Clinical significance of the genetic landscape of pancreatic cancer and implications for identification of potential long-term survivors. Clin Cancer Res. 2012;18: 6339-47.

9. Zhou G, Liu Z, Myers JN. TP53 Mutations in head and neck squamous cell carcinoma and their impact on disease progression and treatment response. J Cell Biochem. 2016;117:2682-92.
10. SHah SP, Roth A, Goya R, Oloumi A, Ha G, et al. The clonal and mutational evolution spectrum of primary triple-negative breast cancers. Nature. 2012; 486:395-9.

11. FReed-Pastor WA, Prives C. Mutant p53: one name, many proteins. Genes Dev. 2012;26:1268-86

12. STrano S, Dell'Orso S, Di Agostino S, Fontemaggi G, Sacchi A, Blandino G. Oncogene 2007; 26:2212-2219.

13. LEroy B, Fournier $\mathrm{L}$, Ishioka $\mathrm{C}$, et al. The TP53 website: an integrative resource centre for the TP53 mutation database and TP53 mutant analysis. Nucleic Acids Res. 2013;41:D962-9.

14. MUller PA, Vousden KH. P53 mutations in cancer. Nat Cell Biol. 2013;15:2-8.

15. GOh AM, Coffill CR, Lane DP. The role of mutant p53 in human cancer. J Pathol. 2011:223:116-26.

16. Guha T, Malkin D. Inherited TP53 mutations and the li-Fraumeni syndrome. Cold Spring Harb Perspect Med. 2017:3, 7(4)

17. DI Agostino S, Strano S, Emiliozzi V, Zerbini V, Mottolese M, et al. Gain of function of mutant p53: the mutant p53/NF-Y protein complex reveals an aberrant transcriptional mechanism of cell cycle regulation. Cancer Cell. 2006:10:191-202

18. VAlenti F, Ganci F, Fontemaggi G, Sacconi A, Strano S, et al. Gain of function mutant p53 proteins cooperate with E2F4 to transcriptionally downregulate RAD17 and BRCA1 gene expression. Oncotarget. 2015;6:5547-66.

19. FOntemaggi G, Dell'Orso S, Trisciuoglio D, Shay T, Melucci E, et al. The execution of the transcriptional axis mutant p53, E2F1 and ID4 promotes tumor neo-angiogenesis. Nat Struct Mol Biol. 2009;16:1086-93.

20. STambolsky P, Tabach Y, Fontemaggi G, Weisz L, Maor-Aloni R, et al. Modulation of the vitamin D3 response by cancer-associated mutant p53. Cancer Cell. 2010;17:273-85.

21. FReed-Pastor WA, Mizuno H, Zhao X, Langerod A, Moon SH, RodriguezBarrueco $\mathrm{R}$, et al. Mutant p53 disrupts mammary tissue architecture via the mevalonate pathway. Cell. 2012;148:244-58.

22. DI Agostino $S$, Sorrentino $G$, Ingallina $E$, Valenti $F$, Ferraiuolo $M$, et al. YAP enhances the pro-proliferative transcriptional activity of mutant p53 proteins. EMBO Rep. 2016:17:188-201.

23. SOrrentino G, Ruggeri N, Specchia V, Cordenonsi M, Mano M, Dupont S, Manfrin A, Ingallina E, Sommaggio R, Piazza S, Rosato A, Piccolo S, Del Sal G. Metabolic control of YAP and TAZ by the mevalonate pathway. Nat Cell Biol. 2014:16:357-66.

24. WAlerych D, Lisek K, Sommaggio R, Piazza S, et al. Proteasome machinery is instrumental in a common gain-of-function program of the p53 missense mutants in cancer. Nat Cell Biol. 2016;18:897-909.

25. Cordani M, Oppici E, Dando I, Butturini E, Dalla Pozza E, et al. Mutant p53 proteins counteract autophagic mechanism sensitizing cancer cells to mtor inhibition. Mol Oncol. 2016;10:1008-29.

26. VErduci L, Ferraiuolo M, Sacconi A, Ganci F, Vitale J, et al. The oncogenic role of circpvt1 in head and neck squamous cell carcinoma is mediated through the mutant p53/YAP/TEAD transcription-competent complex. Genome Biol. 2017;18:237.

27. ADorno M, Cordenonsi M, Montagner M, Dupont S, Wong C, et al. A mutant-p53/Smad complex opposes p63 to empower tgfbeta-induced metastasis. Cell. 2009;137:87-98.

28. GRugan KD, Vega ME, Wong GS, Diehl JA, Bass AJ, et al. A common p53 mutation (R175H) activates c-met receptor tyrosine kinase to enhance tumor cell invasion. Cancer Biol Ther. 2013;14:853-9.

29. SAuer L, Gitenay D, Vo C, Baron VT. Mutant p53 initiates a feedback loop that involves Egr-1/EGF receptor/ERK in prostate cancer cells. Oncogene. 2010;29:2628-37.

30. Muller PA, Trinidad AG, Timpson P, Morton JP, Zanivan S, et al. Mutant p53 enhances MET trafficking and signalling to drive cell scattering and invasion. Oncogene. 2013;32:1252-65.

31. Girardini JE, Napoli M, Piazza S, Rustighi A, Marotta C, et al. A Pin1/ mutant p53 axis promotes aggressiveness in breast cancer. Cancer Cell. 2011;20:79-91.

32. Irwin MS. Family feud in chemosensitvity: p73 and mutant p53. Cell Cycle. 2004;3:319-23.

33. Strano S, Blandino G. P73-mediated chemosensitivity: a preferential target of oncogenic mutant p53. Cell Cycle. 2003;2:348-9.

34. Liu K, Ling S, Lin WC. Topbp1 mediates mutant p53 gain of function through NF-Y and p63/p73. Mol Cell Biol. 2011;31:4464-81.

35. HAnel W, Moll UM. Links between mutant p53 and genomic instability. J Cell Biochem. 2012;113:433-9. 
36. TErzian T, Suh YA, Iwakuma T, Post SM, Neumann M, et al. The inherent instability of mutant p53 is alleviated by Mdm2 or p16ink4a loss. Genes Dev. 2008;22:1337-44.

37. HAlazonetis TD, Gorgoulis VG, Bartek J. An oncogene-induced DNA damage model for cancer development. Science. 2008;319:1352-5.

38. Llu Y, Chen C, Xu Z, Scuoppo C, Rillahan CD, Gao J, et al. Deletions linked to TP53 loss drive cancer through p53-independent mechanisms. Nature. 2016; 531:471-5.

39. Mllner J, Medcalf EA, Cook AC. Tumor suppressor p53: analysis of wild-type and mutant p53 complexes. Mol Cell Biol. 1991;11:12-9.

40. WIllis A, Jung EJ, Wakefield T, Chen X. Mutant p53 exerts a dominant negative effect by preventing wild-type p53 from binding to the promoter of its target genes. Oncogene. 2004;23:2330-8.

41. YIn Y, Tainsky MA, Bischoff FZ, Strong LC, Wahl GM. Wild-type p53 restores cell cycle control and inhibits gene amplification in cells with mutant p53 alleles. Cell. 1992;70:937-48.

42. LAng GA, Iwakuma T, Suh YA, Liu G, Rao VA, et al. Gain of function of a p53 hot spot mutation in a mouse model of li-Fraumeni syndrome. Cell. 2004; 119:861-72.

43. HAupt $Y$, Maya R, Kazaz A, Oren M. Mdm2 promotes the rapid degradation of p53. Nature. 1997:387:296-9.

44. TOledo F, Wahl GM. Regulating the p53 pathway: in vitro hypotheses, in vivo veritas. Nat Rev Cancer. 2006;6:909-23.

45. LUkashchuk N, Vousden KH. Ubiquitination and degradation of mutant p53. Mol Cell Biol. 2007;27:8284-95.

46. WU X, Bayle JH, Olson D, et al. The p53-mdm-2 autoregulatory feedback loop. Genes Dev. 1993;7:1126-32.

47. Vljayakumaran R, Tan KH, Miranda PJ, Haupt S, Haupt Y. Regulation of mutant p53 protein expression. Front Oncol. 2015;5:284-8.

48. ALexandrova EM, Mirza SA, Xu S, Schulz-Heddergott R, Marchenko ND, Moll UM. P53 loss-of-heterozygosity is a necessary prerequisite for mutant p53 stabilization and gain-of-function in vivo. Cell Death Dis. 2017;8:e2661

49. WHitesell L, Lindquist SL. HSP90 and the chaperoning of cancer. Nat Rev Cancer. 2005;5:761-72.

50. ALexandrova EM, Marchenko ND. Mutant p53 - heat shock response oncogenic cooperation: a new mechanism of cancer cell survival. Front Endocrinol (Lausanne). 2015:6:53.

51. ALexandrova EM, Yallowitz AR, Li D, Xu S, Schulz R, Proia DA, Lozano G, Dobbelstein M, Moll UM. Improving survival by exploiting tumour dependence on stabilized mutant p53 for treatment. Nature. 2015;523:352-6.

52. LI D, Marchenko ND, Moll UM. SAHA shows preferential cytotoxicity in mutant p53 cancer cells by destabilizing mutant p53 through inhibition of the HDAC6-Hsp90 chaperone axis. Cell Death Differ. 2011;18:1904-13.

53. TRepel J, Mollapour M, Giaccone G, Neckers L. Targeting the dynamic HSP90 complex in cancer. Nat Rev Cancer. 2010;10:537-49.

54. SLingerland M, Guchelaar HJ, Gelderblom H. Histone deacetylase inhibitors: an overview of the clinical studies in solid tumors. Anti-Cancer Drugs. 2014;25:140-9.

55. WAlerych D, Lisek K, Del Sal G. Mutant p53: one, no one, and one hundred thousand. Front Oncol. 2015;5:289.

56. HAupt S, Raghu D, Haupt Y. Mutant p53 drives cancer by subverting multiple tumor suppression pathways. Front Oncol. 2016;6:12.

57. MAsciarelli S, Fontemaggi G, Di Agostino S, Donzelli S, Carcarino E, Strano S, Blandino G. Gain-of-function mutant p53 downregulates mir-223 contributing to chemoresistance of cultured tumor cells. Oncogene. 2014:33:1601-8.

58. Florini C, Cordani M, Padroni C, Blandino G, Di Agostino S, Donadelli M. Mutant p53 stimulates chemoresistance of pancreatic adenocarcinoma cells to gemcitabine. Biochim Biophys Acta. 2015;1853:89-100.

59. Ferraiuolo M, Di Agostino S, Blandino G, Strano S. Oncogenic intra-p53 family member interactions in human cancers. Front Oncol. 2016;6:77.

60. COrdani M, Pacchiana R, Butera G, D'Orazi G, Scarpa A, Donadelli M. Mutant p53 proteins alter cancer cell secretome and tumour microenvironment involvement in cancer invasion and metastasis. Cancer Lett. 2016;376:303-9.

61. PRuszko M, Milano E, Forcato M, Donzelli S, Ganci F, et al. The mutant p53ID4 complex controls VEGFA isoforms by recruiting Incrna MALAT1. EMBO Rep. 2017;18:1331-51.

62. BUhaescu I, Izzedine H. Mevalonate pathway: a review of clinical and therapeutical implications. Clin Biochem. 2007:40:575-84.

63. CLendening JW, Pandyra A, Boutros PC, El Ghamrasni S, Khosravi F, Trentin GA, et al. Dysregulation of the mevalonate pathway promotes transformation. Proc Natl Acad Sci U S A. 2010;107:15051-6.
64. PArrales A, Thoenen E, Iwakuma T. The interplay between mutant p53 and the mevalonate pathway. Cell Death Differ. 2017. https://doi.org/10.1038/ s41418-017-0026-y.

65. INgallina E, Sorrentino G, Bertolio R, Lisek K, Zannini A, et al. Mechanical cues control mutant p53 stability through a mevalonate-rhoa axis. Nat Cell Biol. 2018;20:28-35.

66. PArrales A, Ranjan A, lyer SV, Padhye S, Weir SJ, Roy A, et al. DNAJA controls the fate of misfolded mutant p53 through the mevalonate pathway. Nat Cell Biol. 2016;18:1233-43.

67. PAnciera T, Azzolin L, Cordenonsi M, Piccolo S. Mechanobiology of YAP and TAZ in physiology and disease. Nat Rev Mol Cell Biol. 2017;18:758-70.

68. FErraiuolo M, Verduci L, Blandino G, Strano S. Mutant p53 Protein and the Hippo Transducers YAP and TAZ: A Critical Oncogenic Node in Human Cancers. Int J Mol Sci. 2017;18:Pii: E961.

69. NOrdstrom T, Clements M, Karlsson R, Adolfsson J, Gronberg H. The risk of prostate cancer for men on aspirin, statin or antidiabetic medications. Eur J Cancer. 2015:51:725-33.

70. ALliance for Clinical Trials in Oncology. https:/clinicaltrials.gov/ct2/results?Cond= cancer\&term $=$ statin\&cntry $=\&$ state $=\&$ city $=\&$ dist $=$

71. JUnttila MR, de Sauvage FG. Influence of tumour micro-environment heterogeneity on therapeutic response. Nature. 2013;501:346-54.

72. NGuyen DX, Bos PD, Massague J. Metastasis: from dissemination to organspecific colonization. Nat Rev Cancer. 2009:9:274-84.

73. SUn Y, Cheung JM, Martel-Pelletier J, Pelletier JP, Wenger L, et al. Wild type and mutant p53 differentially regulate the gene expression of human collagenase-3 (hmmp-13). J Biol Chem. 2000;275:11327-32.

74. LEung HW, Zhao SM, Yue GG, Lee JK, Fung KP, et al. RA-XII inhibits tumour growth and metastasis in breast tumour-bearing mice via reducing cell adhesion and invasion and promoting matrix degradation. Sci Rep. 2015;5: 16985.

75. COoks T, Pateras IS, Tarcic O, Solomon H, Schetter AJ, et al. Mutant p53 prolongs NF-kb activation and promotes chronic inflammation and inflammation-associated colorectal cancer. Cancer Cell. 2013;23:634-46.

76. YEudall WA, Vaughan CA, Miyazaki H, Ramamoorthy M, Choi MY, et al, Gain-of-function mutant p53 upregulates CXC chemokines and enhances cell migration. Carcinogenesis. 2012:33:442-51.

77. ADdadi Y, Moskovits N, Granot D, Lozano G, Carmi Y, et al. P53 status in stromal fibroblasts modulates tumor growth in an SDF1-dependent manner. Cancer Res. 2010;70:9650-8.

78. MOrselli E, Tasdemir E, Maiuri MC, Galluzzi L, Kepp O, et al. Mutant p53 protein localized in the cytoplasm inhibits autophagy. Cell Cycle. 2008;7:3056-61.

79. Mlhaylova MM, Shaw RJ. The AMPK signalling pathway coordinates cell growth, autophagy and metabolism. Nat Cell Biol. 2011;13:1016-23.

80. ASchauer $L$, Muller PA. Novel targets and interaction partners of mutant $p 53$ gain-of-function. Biochem Soc Trans. 2016:44:460-6.

81. CHoudhury S, Kolukula VK, Preet A, Albanese C, Avantaggiati ML. Dissecting the pathways that destabilize mutant p53: the proteasome or autophagy? Cell Cycle. 2013;12:1022-9.

82. ROdriguez OC, Choudhury S, Kolukula V, Vietsch EE, Catania J, et al. Dietary downregulation of mutant p53 levels via glucose restriction: mechanisms and implications for tumor therapy. Cell Cycle. 2012:11:4436-46.

83. LUnt SY, Vander Heiden MG. Aerobic glycolysis: meeting the metabolic requirements of cell proliferation. Annu Rev Cell Dev Biol. 2011:27:441-64.

84. ZHang C, Liu J, Liang Y, Wu R, Zhao Y, et al. Tumour-associated mutant p53 drives the Warburg effect. Nat Commun. 2013:4:2935.

85. GOel A, Mathupala SP, Pedersen PL. Glucose metabolism in cancer. Evidence that demethylation events play a role in activating type ॥ hexokinase gene expression. J Biol Chem. 2003;278:15333-40.

86. CHristophorou MA, Martin-Zanca D, Soucek L, Lawlor ER, Brown-Swigart L, et al. Temporal dissection of p53 function in vitro and in vivo. Nat Genet. 2005;37:718-26

87. JAckson JG, Lozano G. The mutant p53 mouse as a pre-clinical model. Oncogene. 2013;32:4325-30

88. XUe C, Haber M, Flemming C, Marshall GM, Lock RB, et al. P53 determines multidrug sensitivity of childhood neuroblastoma. Cancer Res. 2007;67: 10351-60.

89. KEnzelmann Broz D, Attardi LD. In vivo analysis of p53 tumor suppressor function using genetically engineered mouse models. Carcinogenesis. 2010;31:1311-8.

90. WAng Y, Suh YA, Fuller MY, Jackson JG, Xiong S, et al. Restoring expression of wild-type p53 suppresses tumor growth but does not cause tumor regression in mice with a p53 missense mutation. J Clin Invest. 2011;121:893-904. 
91. BYkov VJ, Issaeva N, Shilov A, et al. Restoration of the tumor suppressor function to mutant p53 by a low-molecular- weight compound. Nat Med. 2002;8:282-8.

92. BYkov VJ, Issaeva N, Zache N, et al. Reactivation of mutant p53 and induction of apoptosis in human tumor cells by maleimide analogs. J Biol Chem. 2005:280:30384-91.

93. BOu-Hanna C, Jarry A, Lode L, Schmitz I, Schulze-Osthoff K, et al. Acute cytotoxicity of MIRA-1/NSC19630, a mutant p53-reactivating small molecule, against human normal and cancer cells via a caspase-9-dependent apoptosis. Cancer Lett. 2015:359:211-7.

94. WAng T, Lee K, Rehman A, Daoud SS. PRIMA-1 induces apoptosis by inhibiting JNK signaling but promoting the activation of Bax. Biochem Biophys Res Commun. 2007;352:203-12.

95. LAmbert JM, Gorzov P, Veprintsev DB, Soderqvist M, Segerback D, Bergman J, et al. PRIMA-1 reactivates mutant p53 by covalent binding to the core domain. Cancer Cell. 2009;15:376-88.

96. WAssman CD, Baronio R, Demir O", Wallentine BD, Chen CK, Hall LV, et al. Computational identification of a transiently open L1/S3 pocket for reactivation of mutant p53. Nat Commun 2013; 4:1407.

97. ZAndi R, Selivanova G, Christensen CL, Gerds TA, Willumsen BM, Poulsen HS PRIMA-1Met/APR-246 induces apoptosis and tumor growth delay in small cell lung cancer expressing mutant p53. Clin Cancer Res. 2011;17:2830-41.

98. SAha MN, Jiang H, Yang Y, Reece D, Chang H. PRIMA-1Met/APR- 246 displays high antitumor activity in multiple myeloma by induction of p73 and Noxa. Mol Cancer Ther. 2013;12:2331-41.

99. Llang Y, Besch-Williford C, Hyder SM. PRIMA-1 inhibits growth of breast cancer cells by re-activating mutant p53 protein. Int J Oncol. 2009;35:1015-23.

100. LEhmann S, Bykov VJ, Ali D, Andren O, Cherif H, Tidefelt U, et al. Targeting p53 in vivo: a first-in-human study with p53-targeting compound APR-246 in refractory hematologic malignancies and prostate cancer. J Clin Oncol. 2012;30:3633-9.

101. GAndolfi S, Laubach JP, Hideshima T, Chauhan D, Anderson KC, Richardson PG. The proteasome and proteasome inhibitors in multiple myeloma. Cancer Metastasis Rev. 2017;36:561-84.

102. BYkov VJ, Wiman KG. Mutant p53 reactivation by small molecules makes its way to the clinic. FEBS Lett. 2014;588:2622-7.

103. BUllock AN, Fersht AR. Rescuing the function of mutant p53. Nat Rev Cancer. 2001;1:68-76.

104. Sigal A, Rotter V. Oncogenic mutations of the p53 tumor suppressor: the demons of the guardian of the genome. Cancer Res. 2000;60:6788-93.

105. LI Y, Prives C. Are interactions with p63 and p73 involved in mutant p53 gain of oncogenic function? Oncogene. 2007;26:2220-5.

106. SAntini S, Di Agostino S, Coppari E, Bizzarri AR, Blandino G, Cannistraro S. Interaction of mutant p53 with p73: a surface Plasmon resonance and atomic force spectroscopy study. Biochim Biophys Acta. 2014;1840:1958-64.

107. MÜller M, Schleithoff ES, Stremmel W, Melino G, Krammer PH, Schilling T. One, two, three-p53, p63, p73 and chemosensitivity. Drug Resist Updat. 2006;9:288-306.

108. ZAwacka-Pankau J, Kostecka A, Sznarkowska A, Hedstrom E, Kawiak A. P73 tumor suppressor protein: a close relative of p53 not only in structure but also in anti-cancer approach? Cell Cycle. 2010;9:720-8.

109. Dl Agostino S, Cortese G, Monti O, Dell'Orso S, Sacchi A, et al. The disruption of the protein complex mutantp53/p73 increases selectively the response of tumor cells to anticancer drugs. Cell Cycle. 2008;7: 3440-7.

110. GUida E, Bisso A, Fenollar-Ferrer C, Napoli M, Anselmi C, Girardini JE, Carloni P, Del Sal G. Peptide aptamers targeting mutant p53 induce apoptosis in tumor cells. Cancer Res. 2008;68:6550-8.

111. COlas P, Cohen B, Jessen T, Grishina I, mccoy J, Brent R. Genetic selection of peptide aptamers that recognize and inhibit cyclin-dependent kinase 2. Nature. 1996;380:548-50.

112. TAI P, Eizenberger S, Cohen E, Goldfinger N, Pietrokovski S, Oren M, Rotter V. Cancer therapeutic approach based on conformational stabilization of mutant p53 protein by small peptides. Oncotarget. 2016;7:11817-37.

113. Llu X, Wilcken R, Joerger AC, Chuckowree IS, Amin J, et al. Small molecule induced reactivation of mutant p53 in cancer cells. Nucleic Acids Res. 2013; 41:6034-44

114. HOng B, Prabhu W, Zhang S, van den Heuvel AP, Dicker DT, Kopelovich L, El-Deiry WS. Prodigiosin rescues deficient p53 signaling and antitumor effects via upregulating p73 and disrupting its interaction with mutant p53. Cancer Res. 2014;74:1153-65.
115. Zhang S, Zhou L, Hong B, van den Heuvel AP, Prabhu W, et al. Small-molecule NSC59984 restores p53 pathway signaling and antitumor effects against colorectal cancer via p73 activation and degradation of mutant p53. Cancer Res. 2015;75:3842-52.

116. GArufi A, Pistritto G, Cirone M, D'Orazi G. Reactivation of mutant p53 by capsaicin, the major constituent of peppers. J Exp Clin Cancer Res. 2016;35:136.

117. AGgarwal M, Saxena R, Sinclair E, Fu Y, Jacobs A, et al. Reactivation of mutant p53 by a dietary-related compound phenethyl isothiocyanate inhibits tumor growth. Cell Death Differ. 2016;23:1615-27.

118. ABbas T, Keaton MA, Dutta A. Genomic instability in cancer. Cold Spring Harb Perspect Biol. 2013;5:a012914.

119. JAckson SP. Sensing and repairing DNA double-strand breaks. Carcinogenesis. 2002;23:687-96.

120. ZHa S, Boboila C, Alt FW. Mre11: roles in DNA repair beyond homologous recombination. Nat Struct Mol Biol. 2009;16:798-800.

121. BUis J, Wu Y, Deng Y, Leddon J, Westfield G, Eckersdorff M, Sekiguchi JM, Chang S, Ferguson DO. Mre11 nuclease activity has essential roles in DNA repair and genomic stability distinct from ATM activation. Cell. 2008;135:85-96.

122. SOng $H$, Hollstein M, Xu Y. P53 gain-of-function cancer mutants induce genetic instability by inactivating ATM. Nat Cell Biol. 2007;9:573-80.

123. SChwemmle S, Pfeifer GP. Genomic structure and mutation screening of the E2F4 gene in human tumors. Int J Cancer. 2000;86:672-7.

124. KAstan MB, Bartek J. Cell-cycle checkpoints and cancer. Nature. 2004;432: 316-23.

125. GAnci F, Sacconi A, Bossel Ben-Moshe N, Manciocco V, Sperduti I, et al. Expression of TP53 mutation-associated micrornas predicts clinical outcome in head and neck squamous cell carcinoma patients. Ann Oncol. 2013;24:3082-8.

126. STransky N, Egloff AM, Tward AD, Kostic AD, Cibulskis K, et al. The mutational landscape of head and neck squamous cell carcinoma. Science. 2011:333:1157-60.

127. SAtoh MS, Lindahl T. Role of poly(ADP-ribose) formation in DNA repair. Nature. 1992:356:356-8.

128. AHel I, Ahel D, Matsusaka T, Clark AJ, Pines J, Boulton SJ, West SC. Poly(ADP-ribose)-binding zinc finger motifs in DNA repair/checkpoint proteins. Nature. 2008;451:81-5.

129. Llu C, Srihari S, Cao KA, Chenevix-Trench G, Simpson PT, et al. A fine-scale dissection of the DNA double-strand break repair machinery and its implications for breast cancer therapy. Nucleic Acids Res. 2014:42:6106-27.

130. FOng PC, Boss DS, Yap TA, Tutt A, Wu P, Mergui-Roelvink M, et al. Inhibition of poly(ADP-ribose) polymerase in tumors from BRCA mutation carriers. $\mathrm{N}$ Engl J Med. 2009;361:123-34.

131. WAng M, Wu W, Wu W, Rosidi B, Zhang L, Wang H, lliakis G. PARP-1 and Ku compete for repair of DNA double strand breaks by distinct NHEJ pathways. Nucleic Acids Res. 2006;34:6170-82.

132. LEdermann J, Harter P, Gourley C, Friedlander M, Vergote I, et al. Olaparib maintenance therapy in platinum-sensitive relapsed ovarian cancer. N Engl J Med. 2012:366:1382-92.

133. SAndhu SK, Schelman WR, Wilding G, Moreno V, Baird RD, et al. The poly(ADP-ribose) polymerase inhibitor niraparib (MK4827) in BRCA mutation carriers and patients with sporadic cancer: a phase 1 dose-escalation trial. Lancet Oncol. 2013;14:882-92.

134. KAufman B, Shapira-Frommer R, Schmutzler RK, Audeh MW, Friedlander M, et al. Olaparib monotherapy in patients with advanced cancer and a germline BRCA1/2 mutation. J Clin Oncol. 2015;33:244-50.

135. POdo F, Buydens LM, Degani H, Hilhorst R, Klipp E, et al. Triple-negative breast cancer: present challenges and new perspectives. Mol Oncol. 2010;4: 209-29.

136. SHah SP, Roth A, Goya R, et al. The clonal and mutational evolution spectrum of primary triple-negative breast cancers. Nature. 2012; 486:395:399.

137. PHuah SY, Looi LM, Hassan N, Rhodes A, Dean S, et al. Triple-negative breast cancer and PTEN (phosphatase and tensin homologue) loss are predictors of BRCA1 germline mutations in women with early-onset and familial breast cancer, but not in women with isolated late-onset breast cancer. Breast Cancer Res. 2012;14:R142.

138. LIps EH, Mulder L, Oonk A, van der Kolk LE, Hogervorst FB, Imholz AL, et al. Triple-negative breast cancer: Brcaness and concordance of clinical features with BRCA1-mutation carriers. Br J Cancer. 2013;108:2172-7.

139. GElmon KA, Tischkowitz M, Mackay $H$, Swenerton $K$, Robidoux $A$, et al. Olaparib in patients with recurrent high-grade serous or poorly 
differentiated ovarian carcinoma or triple-negative breast cancer: a phase 2, multicentre, open-label, non-randomised study. Lancet Oncol. 2011;12:852-61.

140. Mlnami D, Takigawa N, Takeda H, Takata M, Ochi N, et al. Synergistic effect of olaparib with combination of cisplatin on PTEN-deficient lung cancer cells. Mol Cancer Res. 2013;11:140-8.

141. CHeng H, Zhang Z, Borczuk A, Powell CA, Balajee AS, Lieberman HB, et al. PARP inhibition selectively increases sensitivity to cisplatin in ERCC1-low non-small cell lung cancer cells. Carcinogenesis. 2013;34:739-49.

142. HIngorani SR, Wang L, Multani AS, Combs C, Deramaudt TB, et al. Trp53R172H and krasg12d cooperate to promote chromosomal instability and widely metastatic pancreatic ductal adenocarcinoma in mice. Cancer Cell. 2005;7:469-83.

143. DE Lange T. Protection ofmammalian telomeres. Oncogene. 2002;21:532-40.

144. HOchreiter AE, Xiao H, Goldblatt EM, et al. The telomerase template antagonist GRN163L disrupts telomere maintenance, tumor growth and metastasis of breast cancer. Clin Cancer Res. 2006:12:3184-92.

145. GOldblatt EM, Gentry ER, Fox MJ, Gryaznov SM, Shen C, Herbert BS. The telomerase template antagonist GRN163L alters MDA-MB-231 breast cancer cell morphology, inhibits growth, and augments the effects of paclitaxel. Mol Cancer Ther. 2009;8:2027-35.

146. Squire CJ, Dickson JM, Ivanovic I, Baker EN. Structure and inhibition of the human cell cycle checkpoint kinase, Wee1A kinase: an atypical tyro- sine kinase with a key role in CDK1 regulation. Structure. 2005;13:541-50.

147. MAsaki T, Shiratori Y, Rengifo W, Igarashi K, Yamagata M, et al. Cyclins and cyclin-dependent kinases: comparative study of hepatocellular carcinoma versus cirrhosis. Hepatology. 2003;37:534-43.

148. MAgnussen Gl, Hellesylt E, Nesland JM, Trope CG, Flørenes VA, Holm R. High expression of wee1 is associated with malignancy in vulvar squamous cell carcinoma patients. BMC Cancer. 2013;13:288.

149. IOrns E, Lord CJ, Grigoriadis A, mcdonald S, Fenwick K, et al. Integrated functional, gene expression and genomic analysis for the identification of cancer targets. PLoS One. 2009;4:e5120.

150. MOser R, Xu C, Kao M, Annis J, Lerma LA, Schaupp CM, et al. Functional kinomics identifies candidate therapeutic targets in head and neck cancer. Clin Cancer Res. 2014;20:4274-88.

151. EGeland EV, Flatmark K, Nesland JM, Florenes VA, Maelandsmo GM, Boye K. Expression and clinical significance of Wee1 in colorectal cancer. Tumour Biol. 2016;37:12133-40

152. KIm HY, Cho Y, Kang H, Yim YS, Kim SJ, Song J, et al. Targeting the WEE1 kinase as a molecular targeted therapy for gastric cancer. Oncotarget. 2016; 7:49902-16.

153. Tlbes R, Bogenberger JM, Chaudhuri L, Hagelstrom RT, Chow D, et al. Rnai screening of the kinome with cytar-abine in leukemias. Bloo. 2012; 119:2863-72.

154. POrter CC, Kim J, Fosmire S, Gearheart CM, van Linden A, et al. Integrated genomic analyses identify WEE1 as a critical mediator of cell fate and a novel therapeutic target in acute myeloid leukemia. Leukemia. 2012;26:1266-76.

155. Magnussen GI, Holm R, Emilsen E, Rosnes AK, Slipicevic A, Flørenes VA. High expression of Wee1 is associ-ated with poor disease-free survival in malignant melanoma: potential for targeted therapy. PLoS One. 2012;7: e38254.

156. SLipicevic A, Holth A, Hellesylt E, Tropé CG, Davidson B, Flørenes VA. Wee1 is a novel independent prognostic marker of poor survival in post-chemotherapy ovarian carcinoma effusions. Gynecol Oncol. 2014;135:118-24.

157. CUneo KC, Morgan MA, Davis MA, Parcels LA, Parcels J, Karnak D, et al. Wee1 kinase inhibitor AZD1775 radiosensitizes hepatocellular carcinoma regardless of TP53 mutational status through induction of replication stress. Int J Radiat Oncol Biol Phys. 2016;95:782-90.

158. Hirai H, Iwasawa Y, Okada M, Arai T, Nishibata T, et al. Small-molecule inhibition of Wee1 kinase by MK-1775 selectively sensitizes p53-deficient tumor cells to DNA-damaging agents. Mol Cancer Ther. 2009;8:2992-3000.

159. Wang Y, Li J, Booher RN, Kraker A, Lawrence T, Leopold WR Radiosensitization SY. Of p53 mutant cells by PD0166285, a novel G(2) checkpoint abrogator. Cancer Res. 2001;61:8211-7.

160. Pappano WN, Zhang Q, Tucker LA, Tse C, Wang J. Genetic inhibition of the atypical kinase Wee1 selectively drives apoptosis of p53 inactive tumor cells. BMC Cancer. 2014;14:430

161. Poeta ML, Manola J, Goldwasser MA, Forastiere A, Benoit N, Califano JA, et al. TP53 mutations and survival in squamous-cell carcinoma of the head and neck. N Engl J Med. 2007;357:2552-61.
162. Skinner HD, Sandulache VC, Ow TJ, Meyn RE, Yordy JS, Beadle BM, et al. TP53 disruptive mutations lead to head and neck cancer treatment failure through inhibition of radiation-induced senescence. Clin Cancer Res. 2012; 18:290-300.

163. SAno D, Xie TX, Ow TJ, Zhao M, Pickering CR, Zhou G, et al. Disruptive TP53 mutation is associated with aggressive disease characteristics in an orthotopic murine model of oral tongue cancer. Clin Cancer Res. 2011;17: 6658-70.

164. LEijen S, Beijnen JH, Schellens JH. Abrogation of the G2 checkpoint by inhibition of Wee-1 kinase results in sensitization of p53-deficient tumor cells to DNA-damaging agents. Curr Clin Pharmacol. 2010;5:186-91.

165. KAwabe T. G2 checkpoint abrogators as anticancer drugs. Mol Cancer Ther. 2004;3:513-9.

166. Chen T, Stephens PA, Middleton FK, Curtin NJ. Targeting the S and G2 checkpoint to treat cancer. Drug Discov Today. 2012;17:194-202.

167. DE Witt Hamer PC, Mir SE, Noske D, Van Noorden CJ, Würdinger T. WEE1 kinase targeting combined with DNA-damaging cancer therapy catalyzes mitotic catastro-phe. Clin Cancer Res. 2011;17:4200-7.

168. WAng Y, Li J, Booher RN, Kraker A, Lawrence T, Leopold WR, et al. Radiosensitization of p53 mutant cells by PD0166285, a novel G(2) checkpoint abrogator. Cancer Res. 2001;61:8211-7.

169. Hirai H, Iwasawa Y, Okada M, Arai T, Nishibata T, et al. Small-molecule inhibition of Wee1 kinase by MK-1775 selectively sensitizes p53-deficient tumor cells to DNA-damaging agents. Mol Cancer Ther. 2009;8:2992-3000.

\section{Submit your next manuscript to BioMed Central and we will help you at every step:}

- We accept pre-submission inquiries

- Our selector tool helps you to find the most relevant journal

- We provide round the clock customer support

- Convenient online submission

- Thorough peer review

- Inclusion in PubMed and all major indexing services

- Maximum visibility for your research

Submit your manuscript at www.biomedcentral.com/submit
Biomed Central 